Artigos

\title{
Uma Comissão da Verdade no Brasil
} Escravidão, multiculturalismo, história e memória ${ }^{1}$

\author{
A Truth Commission in Brazil \\ Slavery, multiculturalism, history and memory \\ Una Comisión de la Verdad en Brasil \\ Esclavitud, multiculturalismo, historia y memoria \\ Márcia Leitão Pinheiro ${ }^{2}$
}

\begin{abstract}
Resumo: Ao focalizar a Comissão da Verdade da Escravidão Negra no Brasil (Cvenb), apoiada pela Ordem dos Advogados do Brasil (OAB), abordo sua formação e os instrumentos antirracistas que pautam sua atuação. Ainda apresento a reflexão sobre a inscrição da escravidão no contexto da Comissão da Verdade e como é realizada sua proximidade com outra catástrofe histórica. Reflito como a comissão compreende o multiculturalismo e como isso contribui para confrontar a narrativa oficial acerca da nação, que tem sido questionada por segmentos do Movimento Negro. Utilizo material proveniente de observação direta das atividades da Comissão, material de imprensa, vídeos e documentos produzidos pela Comissão.
\end{abstract}

Palavras-chave: Comissão da Verdade; Escravidão; Multiculturalismo; Narrativa.

\begin{abstract}
Focusing on the Commission on the Truth of Black Slavery in Brazil (Cvenb), supported by the Brazilian Bar Association (OAB), I will discuss its creation and the antiracist instruments that guide its performance. I will also present the reflection on the slavery in the context of the Truth Commission (TC) and how its proximity with other historical catastrophe is carried out. I analyse how the Commission interprets multiculturalism and how this understanding confronts the official narrative concerning the concept of the nation, which has been questioned by segments of the Black Movement. The examined material derives from direct observation of the Commission's activities, press material, videos and documents produced by the Commission itselves.
\end{abstract}

Keywords: Truth Commission; Slavery; Multiculturalism; Narrative.

\footnotetext{
${ }^{1}$ Este artigo resulta do projeto "Tempo da 'verdade': categorias e articulações na investigação da escravidão e seus efeitos na atualidade no estado do Rio de Janeiro". Agradeço ao Instituto de Estudos Sociais e Políticos (Iesp) da Universidade do Estado do Rio de Janeiro (Uerj), pelo apoio dado à realização da pesquisa e à redação deste artigo. Sou também grata aos pareceristas anônimos deste periódico pela leitura e valiosas sugestões.

${ }^{2}$ Universidade Estadual do Norte Fluminense Darcy Ribeiro (Uenf, Campos dos Goytacazes, RJ, Brasil).

autora.dados_biográficos
}

Civitas, Porto Alegre, v. 18, n. 3, p. 683-698, set.-dez. 2018

Este artigo está licenciado sob forma de uma licença Creative Commons Atribuição 4.0 Internacional, que permite uso irrestrito, distribuição e reprodução em qualquer meio, desde que a publicação original seja corretamente citada. https://creativecommons.org/licenses/by/4.0/deed.pt_BR 
Resumen: En este texto abordo el tema de la Comisión de la Verdad de la Esclavitud Negra (Cvenb), incentivada por la Orden de los Abogados de Brasil (OAB). Trato de su formación y los instrumentos antirracistas que pautan su actuación. También realizo una reflexión sobre la propia inscripción de la esclavitud en el contexto de la Comisión de la Verdad y como eso se aproxima de otra catástrofe histórica. Intento mostrar como la comisión dialoga con el escenario multicultural y, por último, analizo la confrontación de segmentos do del Movimiento Negro con la narrativa oficial de la nación. Utilizo material proveniente de observación directa de las actividades de la Comisión, material de la prensa escrita, videos y documentos producidos por la Cmisión.

Palabras clave: Comisión de la Verdad; Esclavitud; Multiculturalismo; Narrativa.

Em dezembro de 2015, aconteceu, no auditório da Ordem dos Advogados do Brasil (OAB), seccional Rio de Janeiro, a entrega do relatório parcial da Comissão Estadual da Verdade da Escravidão Negra no Brasil, em vigência no estado do Rio de Janeiro (Cvenb/RJ). Isso ocorreu diante de organizações do Movimento Negro da cidade e do estado, de dirigentes da OAB estadual e federal, de integrantes de universidades e de autoridade policial. Durante a cerimônia, depois dos pronunciamentos de membros da Cvenb/Nacional e do Rio de Janeiro, o presidente da OAB Nacional à época parabenizou os integrantes da comissão e do Movimento Negro e ressaltou, ao enfatizar o princípio da igualdade, que a comissão estaria inscrita no contexto de "releitura da história". ${ }^{1}$

A ideia de a sociedade brasileira não ser multicultural ${ }^{2}$ perpassa a proposta da investigação da escravidão negra, por se entender que o país ainda não desenvolveu a consciência da convivência não hierárquica entre brancos e negros. Para tanto, tem sido destacado o multiculturalismo como um elemento que deve marcar os embates contra o racismo e as construções históricas que o perpetuam.

Os temas do racismo e da discriminação étnico-racial não são estranhos ao dispositivo da Comissão da Verdade (CV), considerando as especificidades da África do Sul e da Colômbia, por exemplo. Apesar de a comissão sulafricana apurar os abusos cometidos no passado, sua atuação tem sido criticada por causa da atenção dada às consequências da política racial e da pressão colonial na organização da sociedade e na violência em seu interior (Ross, 2006). Na Colômbia, cuja comissão tem por foco a reconciliação nacional, a reparação étnica aparece como ponto do debate sobre como contemplar as

\footnotetext{
${ }^{1}$ Depoimento disponível em: <https://www.youtube.com/watch?v=L-MjfUdSCL0>.

${ }^{2}$ As categorias destacadas em itálico são correntes no contexto pesquisado.
} 
comunidades negras e indígenas em relação à perda de territórios e violações de direitos básicos com o conflito armado. No entanto, é apontado que a proposta é limitada ao focalizar o tempo recente e não as "heridas o daños históricos" que fazem parte das reivindicações desses povos (Mosquera et al., 2007; Castillejo, 2015, p. 30).

A partir da concepção pertinente ao âmbito de esclarecimento histórico e alteração política, que é caracterizado pela afirmação do direito à verdade, à memória e à reparação, interessa, neste artigo, focalizar como é balizada a inscrição da escravidão negra no contexto da CV. Ainda busco refletir como a comissão, ao se voltar à produção da verdade, concebe e relaciona o multiculturalismo em sua argumentação e como isso implica no questionamento da narrativa sobre a sociedade brasileira.

Este artigo apresenta quatro partes. Na primeira, informo como a Cvenb foi concebida, formada e quais as bases para a construção da verdade sobre a escravidão negra. Sua justificativa ainda compreende a referência ao holocausto, para ressaltar a amplitude e a racionalidade das práticas escravocratas e sua implicação na sociedade brasileira. Na segunda, focalizo os temas relevantes na investigação realizada e como isso se associa a uma crítica e, ao mesmo tempo, à apresentação de uma concepção de multiculturalismo. Na terceira, será visto como o fazer da comissão compreende um embate com uma narrativa histórica sobre a escravidão. Por fim, na quarta parte, apresento uma conclusão sobre a comissão e como a construção da verdade implica em cenário de questionamento da sociedade e de ultrapassagem da dicotomia entre memória e história.

Para a elaboração deste artigo, utilizo documentos relacionados à comissão nacional e sua congênere no estado do Rio de Janeiro (Cvenb/RJ) - Relatório parcial e a Metodologia da Comissão Nacional da Verdade da Escravidão Negra (Cfoab, 2015). Recorro ainda a materiais produzidos pela imprensa, outros destinados à divulgação das ações da comissão e vídeos de audiências públicas realizadas no estado do Rio de Janeiro.

\section{Comissão da escravidão: surgimento}

O dispositivo Comissão da Verdade (CV) tem sido aplicado, desde a década de 1980, em diversos países - Colômbia, Argentina, Chile, África do Sul, Uganda, Serra Leoa, Haiti, El Salvador, por exemplo. Sua característica é o enfrentamento do passado como parte de proposta de gestão política, que tem sido elaborada de acordo com cada realidade nacional (Hayner, 2006). A $\mathrm{CV}$ e outros mecanismos de mudança política podem enfatizar esse embate e a circulação de categorias-chave, como "verdade", "violência", "reco- 
nhecimento", "reparação", "futuro", “vítima", "memória”, que também passam a fazer parte do cotidiano daqueles afetados pela violência (Reáteguy, 2012).

No Brasil, desde meados da década de 1970, algumas iniciativas contribuíram para denunciar a violência durante o regime militar, outras cuidaram de reivindicar anistia para os militantes políticos e investigar a repressão política praticada no país. Desse modo, elas cooperaram com uma atmosfera voltada ao esclarecimento das violações dos direitos humanos e promoção do direito à memória e à verdade. Em 2011, o executivo brasileiro sancionou a lei que criou a Comissão Nacional da Verdade (CNV), a qual visa apurar a estrutura, os locais e as instituições implicadas nas violações políticas, entre os anos de 1946 e 1988. Assim, a CNV corroborou a participação do país no contexto de produção de verdade sobre regimes políticos e suas ações contra os direitos humanos, algo já realizado por países vizinhos como a Argentina, desde 1983, e o Chile, desde 1989 (Brasil, 2014).

Com a implantação da CNV, o Conselho Federal da Ordem dos Advogados do Brasil (Cfoab) criou, em 2012, uma CV sobre o período da ditadura militar no Brasil e a resistência de advogados. No mesmo ano, a OAB/RJ constituiu uma comissão para apurar a atuação da justiça militar no período de repressão política. Em 2014, o Cfoab aprovou a Comissão Nacional da Verdade da Escravidão Negra (Cvenb/Nacional), cuja posse aconteceu em fevereiro de 2015, com cerca de 50 componentes - advogados, membros do Ministério Público, institutos de pesquisa de cultura afro-brasileira e pesquisadores -, e a criação de congêneres em estados e municípios. ${ }^{3}$ Ainda em 2014, o Cfoab encaminhou ofício à presidenta da república Dilma Rousseff à época, para solicitar a criação de uma comissão para investigar a escravidão no Brasil no âmbito do poder executivo, porém isso não aconteceu.

A Cvenb foi proposta por advogados que estavam reunidos numa conferência nacional e atentos ao cenário de investigação da verdade no país. $\mathrm{O}$ interesse estava em abordar a escravidão e promover o tema da reparação, pois aquela prática havia sido caracterizada por atos criminosos que envolveram a instância estatal. Na congênere do Rio de Janeiro, foi estabelecida uma rede formada por especialistas em direito, entidades de representação e organizações do Movimento Negro. ${ }^{4}$ Os membros desse conjunto têm formação diversa -

\footnotetext{
${ }^{3}$ Desde 2015, alguns estados e municípios contam com alguma composição da Cvenb, a saber: Espírito Santo, Rio de Janeiro, Minas Gerais, Bahia, Pará, São Paulo, Amazonas e Paraná e, por fim, os municípios de Santos, Campinas e Sorocaba.

${ }^{4}$ Podem ser contados grupos de cultura afro-brasileira, comunidades quilombolas, sindicato, órgãos de defesa pública, conselho de direitos do negro e superintendência de promoção de igualdade racial e Comissão da Igualdade Racial da OAB, organizações de pesquisa e educação sobre a população negra.
} 
direito, ciências sociais e humanas -, e respondem pela formatação, decisão, articulação e ação da comissão.

Em 2015, em audiência pública no salão nobre da Câmara dos Vereadores da cidade do Rio de Janeiro, Marcelo Dias, então presidente da Cvenb/RJ, advogado e militante étnico-racial, explicou o foco da comissão ao dizer que:

a nossa comissão, a Comissão da Escravidão Negra tem um trabalho muito importante para fazer neste país. É combater o extermínio da juventude negra, é combater a intolerância religiosa contra as religiões de matriz africana. É resgatar aquilo que nos foi tirado. ${ }^{5}$

Ao enumerar aquilo que tem afetado a população negra, ele explicitou que a atividade não deveria ficar restrita ao passado, e sim promover também uma profunda reflexão sobre o que se vive - o presente - e como será a vida o futuro. Dessa forma, sustenta-se a investigação sobre a escravidão no país e as conclusões acerca da responsabilidade do estado brasileiro. Voltarei a este ponto mais adiante.

O trabalho da comissão está ancorado em instrumentos internacionais, como a Declaração de Durban, resultado da Conferência Mundial contra o Racismo, a Discriminação Racial, a Xenofobia e Intolerâncias Correlatas, realizada em 2001. Esse documento, uma referência para as organizações do Movimento Negro no Brasil e da América Latina (Lao-Montes, 2013; Igreja; Agudelo, 2014), denuncia a escravidão e o tráfico de seres humanos como crimes contra a humanidade. Ainda ressalta a verdade como elemento histórico e adequado à exposição dos "crimes e injustiças do passado", contribuindo para a "reconciliação internacional e para a criação de sociedades baseadas na justiça, na igualdade e na solidariedade", conforme o artigo 106. Ainda são citadas: a Convenção Internacional sobre a Eliminação de todas as Formas de Discriminação Racial (1965), que dispõe sobre como eliminar formas de discriminação racial, bem como "prevenir e combater doutrinas e práticas racistas", e a Declaração Universal dos Direitos do Homem (1948), que destaca a igualdade e a liberdade. ${ }^{6}$

\footnotetext{
${ }^{5}$ Depoimento disponível em: <https://www.youtube.com/watch?v=kwbSzidk6CY>.

${ }^{6}$ São citados outros documentos: Convenção para a Prevenção e Repressão do Crime de Genocídio (1948), Convenção sobre a Imprescritibilidade dos Crimes de Guerra e dos Crimes contra a Humanidade (1968), Convenção Internacional sobre a Supressão e Punição do Crime de Apartheid (1973), Estatuto de Roma (1998), que instituiu o Tribunal Penal Internacional, Convenção N. 29 de Abolição do Trabalho Forçado (1930), Convenção n. 105 sobre Abolição do Trabalho Forçado (1957), Convenção Interamericana contra o Racismo, a Discriminação Racial e Formas Correlatas de Intolerância.
} 
O texto do Conselho Federal da Ordem dos Advogados do Brasil (Cfoab), que define a metodologia a ser seguida, evidencia que a formação da comissão e sua proposição podem ser compreendidas se relacionadas ao ambiente nacional, que conta com a Constituição Federal (CF), sancionada em 1988. Ela afirma o estado democrático de direito, o "repúdio ao racismo", os direitos culturais e os direitos coletivos. O documento também contempla o Estatuto da Igualdade Racial (2010), voltado ao combate da discriminação racial ou étnico-racial e à defesa de ações afirmativas.

Essas referências respaldaram a elaboração do relatório parcial da Cvenb/ $\mathrm{RJ}$, que, por sua vez, faz menção à colônia e ao império, sendo este apresentado como um período no qual o estado estava imbricado de algum modo com a escravidão. Isso se deu ao legitimar prisões, castigos físicos e penas de morte para os cativos rebelados e ainda impossibilitou recursos à condenação. Com isso, o relatório parcial qualifica a vigência de um antigo "estado racial de exceção", pois foram cometidos atos pelo aparato estatal contra a população negra. Tais fazeres, a captura, o tráfico transatlântico e a escravidão passaram a ser apresentados como crimes e definidos como genocídio.

Para relacionar a escravidão e seus efeitos ao cenário da $\mathrm{CV}$, o relatório parcial faz referência ao holocausto judeu, quando se trata de falar sobre os danos ou as fraturas sociais ligadas a políticas estatais. O emprego desses vocábulos ocorre com a finalidade de apontar a anterioridade e a persistência de política de extermínio, que se estende do período colonial ao cotidiano atual da população negra - afetada por maior encarceramento e ações letais.

A mobilização da categoria empregada para se referir ao extermínio produzido pelo estado nazista não é incomum, posto que já feito por Abdias do Nascimento (1978) ao refletir sobre os ataques direcionados aos indivíduos, às instituições e aos sentimentos religiosos da população negra. Em outra ocasião, Nascimento, em palestra proferida na câmara dos deputados em Washington, no ano de 1980, destacou o trabalho de africanos para a construção da nação, pois criaram riquezas, que foram apropriadas por brancos. Ele afirmava que a entrada e a permanência dos africanos para o trabalho forçado no país foram marcadas pela "estrutura e estratégia de dominação racial", com ampla duração histórica, caracterizando um "holocausto" de africanos (Nascimento, 1982, p. 25).

O uso desse vocábulo tem sido corrente para classificar situações de perseguições e extermínios e, como diagnosticou Hannah Arendt (1999), está relacionado à ficção do inimigo, da falta de empatia, da legitimação de práticas burocráticas e técnicas de ataque. Essas são pensadas não somente como expressão do "mal radical", mas, sobretudo, no registro do "banal", 
podendo-se, assim, estender a categoria para além do estado nazista (Stolcke, 2002). Nesse sentido, o fenômeno produzido por esse estado tem sido mobilizado para balizar reflexões sobre o apartheid sul-africano, praticado também por um estado que oprimiu por vias legais e policiais, "executou judicialmente" e explorou economicamente os "não brancos" (Appiah, 1997, p.36). Esse acontecimento histórico figura na atualidade como paradigma para refletir e discutir práticas contra os direitos humanos (Huyssen, 2014), viabilizando imbricações com eventos nacionais e internacionais.

\section{Encontros e questões no contexto da verdade}

Durante a entrega do relatório parcial na $\mathrm{OAB} / \mathrm{RJ}$ muito se falou em expor a escravidão e o que ela causou no país. Nesse sentido, várias iniciativas realizadas pela Cvenb/RJ podem ser ressaltadas: visitas a comunidades quilombolas, a antigas fazendas e a arquivo público para coleta de indícios sobre a escravização. A comissão ainda promoveu audiências e reuniões públicas, e tais encontros formaram um espaço de manifestação integrado por vozes da população local (OAB/RJ, 2015). Seus depoimentos enfatizaram situações diversas, como ataques direcionados às práticas religiosas afrobrasileiras. Docentes da educação básica afirmaram a dificuldade em desenvolver atividades sobre história da África e a cultura afro-brasileira, conforme estabelece a lei 10.639/03, que altera a Lei de Diretrizes e Bases da Educação Nacional. Outros expuseram as formas de violência que afetam os corpos de jovens e de mulheres negras e ainda denunciaram a insegurança do direito à terra ocupada por famílias negras em área rural ou na cidade. ${ }^{7}$

Duas atividades podem contribuir para explicitar a participação de diferentes grupos e os temas que corroboram o objetivo da comissão. Elas foram realizadas na cidade do Rio de Janeiro, em 2015 e em 2018, com integrantes das religiões de matrizes afro-brasileiras. A primeira ocorreu no Centro de Tradições Afro-Brasileiras (Cetrab), localizado na zona norte da cidade, e reuniu representantes da umbanda e do candomblé de diferentes nações - Jeje, Mahin, Ketu e Efon. Em tal encontro, aconteceu a discussão acerca da luta para enfrentar as discriminações religiosas e a elaboração de um estatuto para regular os direitos dos povos tradicionais de matrizes africanas (OAB/RJ, 2015).

O segundo encontro, em 2018, foi realizado na sede da OAB do Rio de Janeiro e reuniu religiosos do candomblé - nações Bantu, Jeje, Yorubá -, membros da Comissão de Combate à Intolerância Religiosa do Rio de Janeiro

\footnotetext{
${ }^{7}$ Agradeço a Rômulo Barreto a coleta de informações sobre algumas audiências da Cvenb/RJ.
} 
(Ccir-RJ), Fórum de Segurança Alimentar e Nutricional de Povos Tradicionais de Matriz Africana (Fonsanpotma) e Fórum de Mulheres Negras do Rio de Janeiro. O objetivo da atividade foi debater os atos direcionados à integridade física dos fiéis, aos templos, ao conhecimento e às práticas religiosas. Durante o encontro, os ataques foram apontados como expressão do genocídio e não de "intolerância religiosa", como afirmou uma sacerdotisa de origem Bantu. As agressões não foram entendidas como de "ordem interpessoal", porque teriam raízes históricas e estariam ligadas à estrutura da sociedade, que compreende a discriminação racial daquilo não ligado ao polo branco, patriarcal e cristão, conforme enfatizou uma sacerdotisa da tradição Yorubá. ${ }^{8}$

As reuniões com os adeptos das religiões afro-brasileiras evidenciaram as agressões como tema relevante, e elas têm sido problematizadas por seus fiéis. Eles apresentam reflexões contundentes sobre o modo como o país restringe e desqualifica saberes, modos de expressão e de vivência não definidos pela cultura ocidental. Pode-se perceber essa questão no relatório parcial, que afirma:

Nas últimas décadas, vimos surgir e se afirmar uma massa crítica de denúncia dessa realidade distorcida. Os intelectuais afrodescendentes têm pretendido cada vez mais se fazer ouvir e ver. Já não aceitam silenciosamente a condição de invisibilidade. Buscam o multiculturalismo e desestabilizam a falsa cultura hegemônica. Essa nova realidade fez eclodir uma nova conflitualidade. São os conflitos inspirados e aspirados na doutrina e no desejo do reconhecimento (OAB/RJ, 2015, p. 129).

A mobilização militante e o trabalho intelectual realizado enfatizam o multiculturalismo como dimensão de ideias, valores e articulações, sendo visto como viável para refletir sobre a realidade. Esta é apresentada como inadequada por sua valoração da diferença cultural e estética da população negra, bem como caracterizada pela desigualdade entre brancos e negros no tocante às posições sociais. Essas duas dimensões, a cultural e a da desigualdade, são mobilizadas e aparecem como centrais na reflexão realizada no contexto pesquisado.

O campo político registra o termo multiculturalismo quando fala em administrar as demandas de grupos culturais de uma sociedade. Isso tem caracterizado diferentes inscrições de estratégia política referidas a esse substantivo, porém, tem sido enfatizado que não basta admitir a diferença como algo essencializado. $\mathrm{O}$ foco na diversidade e na diferença deve contemplar os

\footnotetext{
${ }^{8}$ Disponível em: <https://www.youtube.com/watch?v=9qCHDMbJ_t0>
} 
posicionamentos que corroboram um espaço político que compreenda variadas vozes, que desafiam as estratégias estatais de concessão de direitos, que nem sempre alteram a hierarquia social e política (Hall, 2003). Mais do que celebrar acriticamente a diversidade, o multiculturalismo tem sido pensado como a busca pela promoção de relações sociais e de política antidiscriminadora, sobretudo por focalizar as desigualdades e exigir medidas para ultrapassá-las, como parte da luta a ser conduzida (Kymlicka, 2014).

Surgido entre 1960/70, no Canadá e em países da Europa, o multiculturalismo se caracteriza por relacionar as dimensões perpassadas pela exclusão e pela diferença: a vida associativa, a educação escolar e o emprego, por exemplo, principalmente com a presença de filhos de imigrantes nesses espaços. Na América Latina, seu registro é mais tardio e com incidência na educação diante da inclusão de conhecimentos e histórias antes ausentes dos currículos escolares. A presença da concepção multicultural na política seria a reelaboração da convivência social, deixando de estar ancorada na diferença e na distância, e sim na diversidade e na tolerância. Dadas as peculiaridades nacionais, o multiculturalismo não pode ser considerado algo homogêneo, mas que apresenta especificidades locais e desafios, "luzes e sombras", que devem ser submetidas à reflexão (Sansone, 2007, p. 24-25).

As alterações constitucionais com perfil multicultural, ocorridas na América Latina, tiveram implicações para os países que contam com forte presença negra e indígena. Mais por ressaltar a diversidade cultural e menos as desigualdades - classe e racial -, o multiculturalismo pode ser entendido como menos radical ou mais retórico, haja vista as iniciativas governamentais voltadas ao reconhecimento e às celebrações de expressões culturais. Apesar disso, a configuração de agenda multicultural na região também tem contribuído para explicitar a interseção entre instâncias da vida social, como violência e racismo, desigualdade e raça. A conquista de direitos relacionados à educação e à terra, como acontece no Brasil e na Colômbia, integra o momento de complexificação do espaço público, com as reivindicações de populações negras e indígenas, no tocante a tais interseções. Assim, o desnudamento das desigualdades e das hierarquias na sociedade possibilita compreender o multiculturalismo não somente como política, mas sim como "campo de luta”, no qual encontramos as expressões reivindicativas de grupos indígenas e negros (Wade, 2011, p. 30).

A partir dessa ideia, podemos compreender a mobilização por cidadania participativa conduzida por organizações negras, que resultou em obtenção de direitos coletivos. Isso é parte de um posicionamento que visa, a combater as 
desigualdades, de um lado, com leis de reparação (Hooker, 2014) e, de outro, com leis afirmativas que promovam a valorização cultural. As participações contra o racismo ressaltam medidas voltadas a políticas de memória, que colocam as dimensões materiais e simbólicas da luta contra as desigualdades (Mosquera et al., 2007).

\section{Confrontar a narrativa oficial}

O multiculturalismo como espaço de luta pode ser assim entendido, quando se aponta para as resistências e as ações que enfatizam o particularismo cultural em relação com o universal. Nesse sentido, ainda compreenderia o embate com as grandes narrativas nacionais baseadas na homogeneidade cultural. As narrativas ou as "micronarrativas" e as "micro-histórias" encontrariam trânsito social e cultural numa expressão da configuração polifônica da sociedade. Nessa perspectiva, o programa multicultural compreenderia diferentes questões e memórias, que caracterizariam sujeitos coletivos e suas identidades sempre em reelaboração diante do confronto com a narrativa hegemônica (Macagno, 2003; 2014).

As manifestações dos participantes das atividades da comissão e o relatório parcial veiculam crítica dirigida à agenda política nacional que, para eles, hierarquiza as diferenças, as culturas, as expressões religiosas e ainda as posições sociais. Por essa via, a realidade vigente faz com que a condição da população negra apareça como algo incontornável e que deve ser enfrentado. Isso compreende questionamentos e conflitos como marca do multiculturalismo vislumbrado e que deve ser direcionado ao que tem caracterizado a sociedade brasileira: a assimetria entre brancos e negros. Para tanto, isso está relacionado com o trabalho da comissão em expor uma história identificada com a ideia da escravidão como algo ameno. A escravidão cordial é apontada como um mito, no sentido de farsa, porque tem ocultado a crueldade do tempo pretérito e alicerçado as desigualdades atuais. ${ }^{9}$ Essa exposição acerca da escravidão e a vinculação temporal integram a concepção do multiculturalismo apresentado

\footnotetext{
${ }^{9} \mathrm{O}$ entendimento de mito como ocultação ou falseamento é aplicado para indicar uma construção da escravidão como fenômeno histórico não violento. Essa elaboração está intimamente relacionada com o chamado "mito da democracia racial", cujo caráter ilusório tem sido apontado como relevante no Brasil pós-escravidão. Sobre ele, tem sido dito que apesar da inscrição da sociedade brasileira no regime democrático e na livre concorrência, a população negra ficou à margem da socialização necessária para a participação no novo cenário econômico, não usufruindo ainda dos direitos e garantias da democracia. Ao estar em curso uma crença de que a sociedade brasileira seja menos restritiva aos negros, a desigualdade social, econômica e política deve ser entendida a partir de uma ligação com o passado. Isso ocorreria com a persistência do "padrão de relações raciais', que aparece como obstáculo para a participação equitativa entre negros e brancos (Fernandes, 2008, p. 302-303).
} 
como elemento de embate com o passado e igualmente visto como um "portal transformador" do presente e do futuro (OAB/RJ, 2015, p. 130).

Segundo o relatório parcial da Cvenb/RJ, além de investigar, cabe à comissão ser um "tribunal da história", na medida em que o documento provoque a reprovação pública dos atos cometidos durante a escravização. Esses são definidos como genocídio e etnocídio - trata-se da criminalização das expressões culturais negras, resultando em seu desaparecimento. Tal posicionamento tem relação com o afirmado pelo dirigente da OAB federal, ao destacar a contribuição da comissão para promover outra leitura da história da escravização no país, pois, no contexto pesquisado, tem sido corrente afirmar que o que se conhece é algo faccioso. Isso é dito, porque a escrita histórica resultaria da não participação de africanos e negros brasileiros em sua elaboração, cujo resultado foi o apagamento de suas memórias e a ocultação da violência da escravidão por parte de alguns intelectuais.

O trabalho realizado pela comissão buscou mapear indícios que possibilitassem classificar práticas da escravidão como crimes e danos, assim como sua conexão com a construção social de raça e cor. Nessa perspectiva, a relatoria da comissão contemplou outra historiografia que explicita os arranjos ultramarinos, os agentes e as relações de poder envolvidas, sobretudo o estado brasileiro. O entendimento é que ele deve ser responsabilizado, já que, sob a coroa portuguesa e no império, o estado esteve implicado com o tráfico transatlântico de pessoas e com a repressão de revoltas por liberdade, que incluiu o recurso a atos de execução. Esta explicitação histórica visaria, segundo Humberto Adami, presidente da Cvenb/Nacional, o enfrentamento da resistência no tocante às políticas compensatórias para a população negra. ${ }^{10}$

A reflexão corrente no contexto pesquisado aponta para um entendimento acerca de uma história, porque ela compreende negação, esquecimento, ocultação do outro por se tratar de escrita-saber, e isso não se resume ao saber disciplinar, mas à prática de dizer sobre o "outro" diante de seu emudecimento - nem sempre voluntário (Certeau, 2011). A comissão, assim, aparece como espaço de articulação, de construção de conhecimento, para confrontar a produção intelectual que tem suprimido a voz, a agência daqueles tratados como subalternos (Spivak, 2010). Esse questionamento da história e da narrativa oficial reporta à reflexão sobre a prática colonial, pois o conhecimento tem pautado o olhar do homem branco e entendido sua violência epistêmica, haja vista a opressão política, o desaparecimento de histórias e

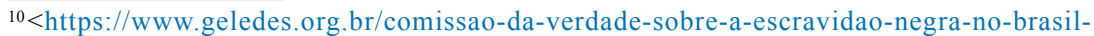
relatorio-parcial-inedito-mostrara-necessidade-de-reparacoes-urgentes-a-populacao-negra/>. 
de vozes. No entanto, o enunciado coloca a possibilidade de transformação em sujeito daquele antes objetificado pelo olhar e pela razão da ciência, pois, com ele, emergiram histórias e conhecimentos, e elas marcam oposição com o enunciado hegemônico (Bhabha, 2005).

A memória é também um eixo forte nos mecanismos de esclarecimento histórico como a CV, por exemplo, pois implicada com o abrandamento do sofrimento e a imaginação de futuro (Ross, 2006) e, no caso, aparece como requisito básico para a reescrita da história ou de escrita de outra história. Isso se dá com a pesquisa de fontes diversas e com depoimentos verbais daqueles alocados na condição de vítima. Mais do que rememorar, compreendo que as falas fazem parte de ato comprometido com a construção de sentido da experiência vivenciada (Rocha; Eckert, 2005). Assim, a memória se torna um significante de relevância para alicerçar os discursos e as práticas de grupos, voltados à emergência de acontecimentos esquecidos, ocultados por uma seleção e gerenciamento institucional do passado, que podem comprometer os direitos humanos (Huyssen, 2014).

Então, diante de situações agudas de violência, dificilmente as memórias, isto é, as interpretações, comporão um registro único acerca do vivido, pois existem diferentes modos de trabalhar com o passado e isso implica em interesse, poder e exclusão (Araújo; Santos, 2007). As lutas políticas podem estar ligadas com o entendimento acerca da memória e não se deve esquecer-se da confluência entre aspectos nacionais, culturais, epistemológicos e políticos. Isso é adequado ao alargamento da democracia e dos direitos, haja vista que as memórias envolvem instituições, acontecimentos e indivíduos - afetados pelo passado -, e que buscam usufruir de "estatuto e direito" (Meneses, 2010, p. 154).

\section{Para fechar}

Neste artigo, busquei contemplar a formação e a atuação de uma comissão e o modo como a escravidão negra integra o cenário da $\mathrm{CV}$, que, em geral, está relacionada com a promoção de outra gestão política. Abordei ainda que o alinhamento ao dispositivo Comissão da Verdade (CV) resulta da articulação de alguns militantes possuidores de conhecimento especializado, de "competência" técnica e pessoal para "interpretar um corpus" pertinente ao campo jurídico, configurando o "direito em dizer o direito" (Bourdieu, 1989, p. 212). Também coube aos segmentos do Movimento Negro participar da empreitada para alargar a base de conhecimento acerca do passado e, assim, dinamizar a arena de luta com o foco na verdade e na reparação. Essa composição entre saberes, fazeres e atores sociais é necessária para o diálogo/ 
confronto com o proceder estatal e a construção das existências daqueles que estão à margem do Estado (Das e Poole, 2008, p. 24).

A investigação da escravidão negra tem a ver com um trabalho que envolve audição de experiências individuais e comunitárias, assim como pesquisa de provas sobre diferentes atos de violência que afetaram e afetam a população negra e como podem ser interpretados como "crimes contra a humanidade". Para tanto, o trabalho realizado por advogados e por organizações do Movimento Negro tem registrado a realização de atividades diversas: audiências públicas, levantamento de provas da escravização e debates. A comissão ainda incorporou um vocabulário que tem possibilitado relacionar o passado histórico e o presente. Isso fica evidente com a comparação com o holocausto, pois explicita a amplitude e a racionalidade da violência que afetou indivíduos e povos submetidos à escravidão negra, que, por sua vez, não deve ser considerada como algo isolado política, geográfica e temporalmente (Castillejo, 2015).

Essa relação entre violência e temporalidade contribui para expor os limites do programa multicultural no país, sobretudo quando problematizados e externalizados os elementos históricos que perfazem o desafio da sociedade brasileira - seja quando se fala na cor da pele, seja quando é ressaltada a diferença cultural. Isso demarca o lugar daqueles que almejam outra "esfera pública", quando contestam as práticas políticas, que não alteraram o quadro de "desvantagem e de exclusão racial" (Hall, 2003, p. 87, 89).

No contexto pesquisado ocorre a apresentação de uma proposta de um multiculturalismo, que deve ultrapassar a retórica, ao se voltar para a articulação entre a diversidade e as desigualdades racial e de classe. Com essa categoria, ocorre a imaginação de uma sociedade não orientada pelo racismo, pela discriminação, mas transformada eticamente com a exposição dos crimes, com a responsabilidade estatal diante do reconhecimento dos danos. O multiculturalismo em destaque é caracterizado como uma agenda de embate contra o desprezo cultural e a assimetria das posições sociais entre brancos e negros.

No relatório parcial é veiculada a tensão com a história oficial diante do destaque dado à memória, porém isso ocorre ao evidenciar a articulação entre o mito da escravidão cordial e a escrita histórica. O que se pode perceber do conflito proposto com a história é que ele não visa a fortalecer dicotomias, mas busca expor seu entrelaçamento com o mito e como a representação histórica compreende modos de refletir sobre o tempo e sobre a vida (LéviStrauss, 1996). Esse conflito ainda expressa que o sistema de explicação não é algo imutável ou congelado, pois outras interpretações podem ser elaboradas 
quando as categorias culturais são colocadas em relação com as ações humanas. Podemos ter o surgimento de novas categorias e novos significados para as existentes, numa demonstração de como os "esquemas convencionais" são repensados, compreendidos e alterados (Sahlins, 2003, p. 8, 79, 121). Isso coopera para o entendimento de o diálogo entre história e memória aparecer como a possibilidade de o grupo reivindicar reconhecimento e reparação, podendo reelaborar ou corrigir a parcialidade da narrativa histórica. Seu efeito pode ser a provocação lançada à "imaginação política" de uma sociedade ao tornar a inclusão um desafio para a vida social (Reátegui, 2012, p. 361).

\section{Referências}

APPIAH, Kwame Anthony. Na casa de meu pai. Rio de Janeiro: Contraponto, 1997.

ARAÚJO, Ana P. Nascimento; SANTOS, Myrian S. História, memória, esquecimento: implicações políticas. Revista Crítica de Ciências Sociais, n. 79, p. 5-111, 2007.

ARENDT, Hannah. Eichmann em Jerusalém: um relato sobre a banalidade do mal. São Paulo: Companhia das Letras, 1999.

BHABHA, Homi K. O local da cultura. Belo Horizonte: Ed. UFMG, 2005.

BRASIL. Relatório da Comissão Nacional da Verdade. Brasília: CNV, 2014.

BRASIL. Lei no 10.639, estabelece a obrigatoriedade da temática "História e Cultura Afro-Brasileira" na rede de ensino, publicada no Diário Oficial da União, 10 jan. 2003, seção 1, p. 1.

BRASIL. Lei no 12.288 , institui o estatuto da igualdade racial, publicada no Diário Oficial da União, 20 jul. 2010, p. 1.

BOURDIEU, Pierre. O poder simbólico. Lisboa: Difel, 1989.

CASTILLEJO, Alejandro. La imaginácion social del porvenir: reflexiones sobre Colombia y el prospecto de una Comisión de la Verdad. Clacso, 2015. <http:// biblioteca.clacso.edu.ar/clacso/becas/20150131091650/CastillejoFinal.pdf>

CERTEAU, Michel de. A escrita da história. Rio de Janeiro: Forense, 2011.

CFOAB. Metodologia da Comissão Nacional da Verdade da Escravidão Negra. Distrito Federal: Cfoab, 2015.

DAS, Veena; POOLE, Deborah. El estado y sus márgenes: etnografias comparadas. Cuadernos de Antropología Social, n. 27, p. 19-52, 2008.

FERNANDES, Florestan. A integração do negro na sociedade de classes. 5. ed. São Paulo: Globo, 2008.

HALL, Stuart. Da diáspora: identidades e mediações culturais. Belo Horizonte: UFMG, 2003.

HAYNER, Priscila B. Truth commissions: an schematic overview. International Review of the Red Cross, v. 88, n. 862, p. 295-310, 2006. <10.1017/S1816383106000531>. 
HOOKER, Juliet. Negociando "negritude" em um estado multicultural: política creole e identidade na Nicarágua. Revista de Estudos e Pesquisas sobre as Américas, v. 8, n. 1, p. 72-88, 2014.

HUYSSEN, Andreas. Culturas do passado-presente: modernismos, artes visuais, políticas de memória. Rio de Janeiro: Contraponto/Museu de Arte do Rio, 2014.

IGREJA, Rebecca; AGUDELO, Carlos. Afrodescendentes na América Latina e Caribe: novos caminhos, novas perspectivas em um contexto global multicultura. Revista de Estudos e Pesquisas sobre as Américas, v. 8, n. 1, p. 13-28, 2014.

KYMLICKA, Will. Multiculturalismo: o sucesso, o fracasso e o futuro. Revista Interfaces Brasil/Canadá, v. 14, n. 18, p. 123-174, 2014.

LAO-MONTES, Agustín. Empoderamiento, descolonización y democracia sustantiva. Afinando principios ético-políticos para las diásporas Afroamericanas. Revista CS, n. 12, p. 53-84, 2013.

LÉVI-STRAUSS, Claude. Antropologia estrutural I. Rio de Janeiro: Tempo Brasileiro, 1996.

MACAGNO, Lorenzo. O dilema multicultural. Curitiba: Editora da UFPR, 2014.

MACAGNO, Lorenzo. Cidadania e cidade (aventuras e desventuras do multiculturalismo). Espaços \& Debates, v. 23, n. 43-44, p. 51-59, 2003.

MENESES, Maria Paula. O passado não morre: a permanência dos espíritos na história de Moçambique. In: Boaventura de Sousa Santos et al. Repressão e memória política no contexto ibero-brasileiro: estudos sobre Brasil, Guatemala, Moçambique, Peru e Portugal. Brasília: Ministério da Justiça; Portugal: Universidade de Coimbra, 2010. p. 150-182.

MOSQUERA, Claudia et al. Introducción: Contribuciones a los debates sobre las memorias de la esclavitud y las afro-reparaciones en Colombia desde el campo de los estudios afro-colombianos, afro-latinoamericanos, afrobrasileros, afroestadounidenses y afro-caribeños. In: Claudia Mosquera; Luiz C. Barcellos (eds.) Afro-reparaciones: memorias de la esclavitud y justicia reparativa para negros, afrocolombianos y raizales. Bogotá: Universidad Nacional de Colombia, 2007. p.11-69.

NASCIMENTO, Abdias do. O negro revoltado. 2. ed. Rio de Janeiro: Nova Fronteira, 1982.

NASCIMENTO, Abdias do. O genocídio do negro brasileiro: processo de um racismo mascarado. Rio de Janeiro: Editora Paz e Terra, 1978.

OAB/RJ. Relatório da Comissão Estadual da Verdade da Escravidão Negra. Rio de Janeiro: OAB/RJ, 2015.

ONU. Convenção Internacional sobre a Eliminação de todas as Formas de Discriminação Racial. Adotada pela Resolução no 2.106-A da Assembleia das Nações Unidas, 21 dez. 1965.

ONU. Conferência Mundial de Combate ao Racismo, Discriminação Racial, Xenofobia e Intolerância Correlata, 3. Declaração de Durban e Plano de Ação. Mistério da Cultura - Fundação Cultural Palmares. Brasília, 2001. 
REÁTEGUI, Félix. As vítimas recordam. Notas sobre a prática social da memória. In: Félix Reátegui (org.). Justiça de transição: manual para a América Latina. Brasília: Comissão de Anistia, Ministério da Justiça; Nova Iorque: Centro Internacional para a Justiça de Transição, 2012. p. 357-378.

ROCHA, Ana Luiza Carvalho da; ECKERT, Cornélia. O tempo e a cidade. Porto Alegre: Editora da Ufrgs, 2005.

ROSS, Fiona. La elaboración de una memoria nacional: la Comisión de Verdad y Reconciliación de Sudáfrica. Cuadernos de Antropología Social, n. 24, p. 51-68, 2006.

SAHLINS, Marshall. Ilhas de história. Rio de Janeiro: Jorge Zahar Ed., 2003.

SANSONE, Livio. Apresentação: que multiculturalismo se quer para o Brasil? Ciência e Cultura, v. 59, n. 2, p. 24-28, 2007.

SPIVAK, Gayatri C. Pode o subalterno falar? Belo Horizonte: Editora UFMG, 2010.

STOLCKE, Verena. Pluralizar o universal: guerra e paz na obra de Hannah Arendt. Mana, v. 8, n. 1, p.93-112, $2002<10.1590 /$ S0104-93132002000100004>.

WADE, Peter. Multiculturalismo y racismo. Revista Colombiana de Antropología, v. 47, n. 2, p. 15-35, 2011.

Recebido em: 17 maio 2018

Aprovado em: 6 out. 2018

Autora correspondente:

Márcia Leitão Pinheiro

Instituto de Estudos Sociais e Políticos

Rua da Matriz, 82 - Botafogo

22260-100 Rio Janeiro, RJ, Brasil

Márcia Leitão Pinheiro <marcialpx@hotmail.com>

Doutora em Sociologia e Antropologia pela Universidade Federal do Rio de Janeiro (UFRJ, Rio de Janeiro, RJ, Brasil), professora da Universidade Estadual do Norte Fluminense Darcy Ribeiro (Uenf, Campos dos Goytacazes, RJ, Brasil). ORCID: https://orcid.org/0000-0001-6695-4585 